\title{
Encefalopathie met elektrische status epilepticus in slaap
}

Epileptische encefalopathie met Elektrische Status Epilepticus in Slaap (ESES) is een epilepsie-syndroom waarbij epileptiforme activiteit vooral, of soms zelfs uitsluitend, tijdens slaap voorkomt. Het komt voor bij kinderen vanaf twee jaar met klinische verschijnselen die gekenmerkt worden door een achteruitgang in cognitief functioneren. Bijna alle kinderen ( $80-90 \%$ ) hebben ook epileptische aanvallen (in waak of vanuit slaap). Hier worden de klinische verschijnselen, etiologie, diagnostiek en behandeling van dit syndroom besproken.

Elektrische Status Epilepticus in Slaap werd in I97I voor het eerst beschreven bij zes kinderen met continue piekgolfcomplexen die optraden tijdens Non-Rapid Eye Movement (NREM)-slaap en verdwenen bij het ontwaken (Patry et al., I97I). 'Continu' wordt gedefinieerd als gedurende meer dan $85 \%$ van de slow wave slaap en daarnaast moest het verschijnsel aanwezig zijn in ten minste drie EEG's verspreid over een periode van minstens een maand (Commission on Classification and Terminology of the International League Against Epilepsy, I989). De continue piekgolfcomplexen gaan niet gepaard met (gelijktijdig zichtbare) klinische verschijnselen. Bij de meeste kinderen is er wel sprake van een matige tot ernstige cognitieve stoornis en af en toe een epileptische aanval. Sindsdien zijn zowel kinderen met cognitieve problemen beschreven met minder dan $85 \%$ van de tijd epileptiforme activiteit gedurende slow wave sleep, als kinderen met een typisch ESES-patroon zonder cognitieve problemen (Saltik et al., 2005).

\section{Achteruitgang in taal, cognitie of gedrag}

De cognitieve stoornissen waarmee kinderen met epileptische encefalopathie met ESES zich presenteren, variëren sterk. Kinderen met het Landau-Kleffner Syndroom (Landau \& Kleffner, 1957) hebben een verworven afasie of auditieve agnosie (het onvermogen om geluiden te herkennen). De cognitieve stoornissen zijn echter vaker wat meer globaal en vallen op door bijvoorbeeld een achteruitgang in schoolresultaten of doordat kinderen aangeboden informatie sneller vergeten en een kortere aandachtsspanne hebben. Deze vorm wordt vaak het continuous spike and wave in slow wave sleep syndrome, ofwel CSWS, genoemd (Fernández et al., 2013). De terminologie wordt echter in de literatuur niet eenduidig gebruikt; vaak wordt ESES gebruikt voor het EEG verschijnsel, terwijl LKS en CSWS twee verschillende klinische syndromen zijn die hierbij voorkomen. Soms worden beide syndromen ook wel aan- geduid met de term 'epileptische encefalopathie met ESES' of 'ESES syndroom'. Veel kinderen met ESES hebben (tevens) ge-dragsproblemen. Kinderen bij wie aanvankelijk de diagnose Rolandische epilepsie of atypische benigne focale epilepsie van de kinderleeftijd werd gesteld kunnen verslechteren en ook ESES met bijkomende cognitieve problemen ontwikkelen (Sánchez Fernández et al., 2012).

\section{Oorzaken}

Bij een derde tot de helft van de kinderen met ESES wordt een onderliggende oorzaak vastgesteld. Het kan gaan om structurele afwijkingen, zoals een congenitaal arteria cerebri media infarct of een perinatale infectie (Nickels \& Wirrell, 2008). Diverse studies laten zien dat de thalamus een belangrijke rol speelt in de pathofysiologie van ESES. Ten eerste blijkt dat na perinataal thalamusletsel op termijn vaak ESES ontstaat (Kersbergen et al., 2013). Bovendien werd zelfs bij kinderen met ESES met een op de MRI als normaal beoordeelde thalamus, een kleiner volume en een afwijkend glucose metabolisme van de thalamus gevonden (Agarwal et al., 20I6; Sánchez Fernández et al., 2017). Ook kan ESES voorkomen in het kader van een genetische afwijking (zoals een GRIN2a-mutatie) (Lemke et al., 20I3).

\section{Diagnostiek}

Wanneer een kind met epilepsie een cognitieve achteruitgang doormaakt, is een EEG met registratie van slaap geïndiceerd. In eerste instantie kan worden volstaan met een slaap-deprivatie-EEG, maar voor het stellen van de diagnose raden wij ten minste een nachtregistratie-EEG aan. De piekgolfindex of spike wave index (SWI) behorend bij het ESES-syndroom wordt berekend door het aantal seconden met epileptiforme activiteit te delen door het totaal aantal seconden dat het EEG wordt gemeten, bij voorkeur over een langere periode non-REM slaap van bij- 


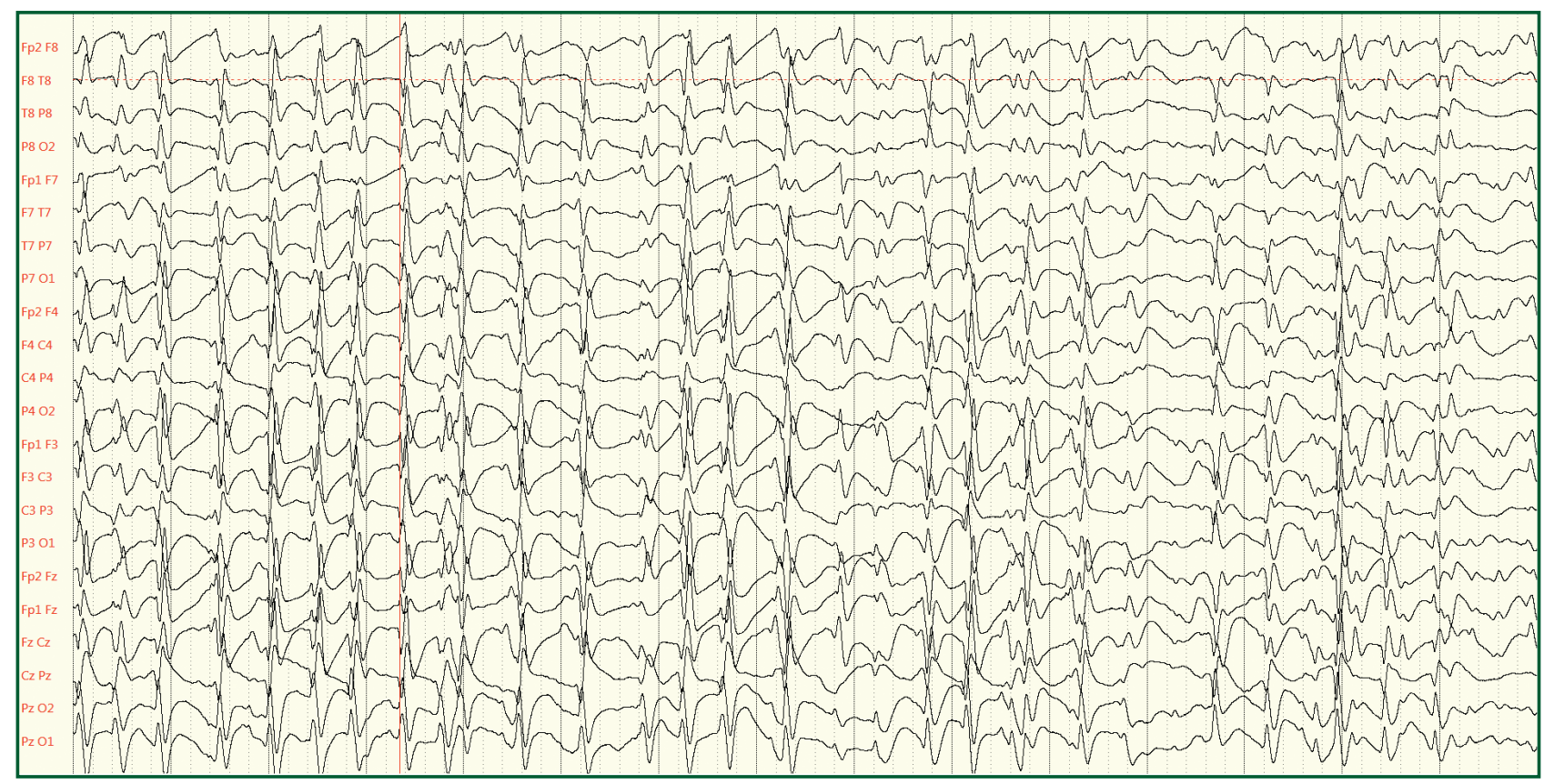

Figuur 1 EEG in non-REM-slaap bij een meisje van 10 jaar met status na thalamusbloeding rond de geboorte en een globale ontwikkelingsachterstand $(400 \mu \mathrm{V} / \mathrm{cm}, 15 \mathrm{sec} /$ pagina $)$

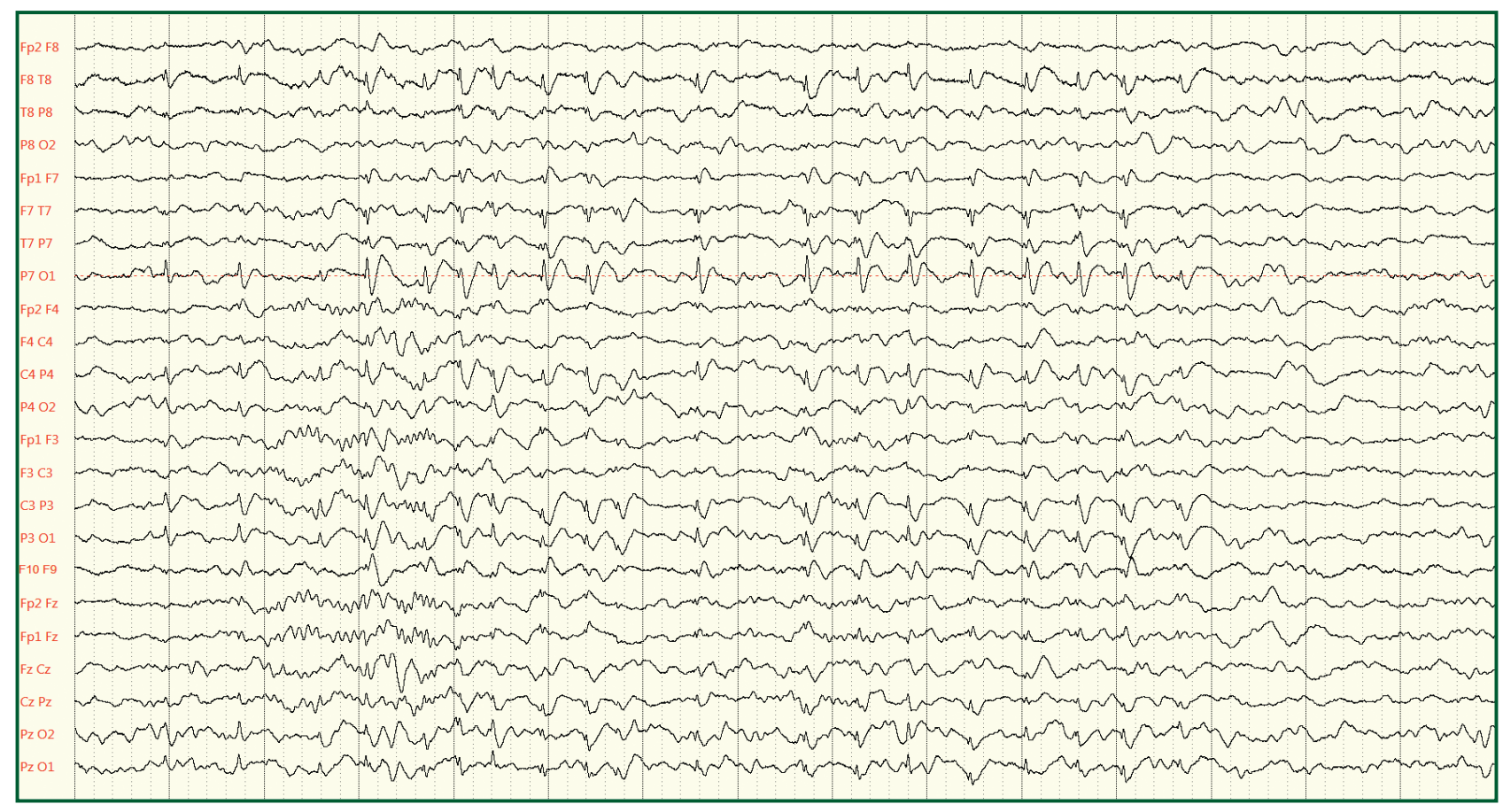

Figuur 2 EEG in non-REM-slaap bij een jongen van vier jaar met een blanco voorgeschiedenis en een verworven afasie $(200 \mu \mathrm{V} / \mathrm{cm}, 15$ $\sec$ / pagina).

voorbeeld tien minuten (Boer, 2009). Tegenwoordig wordt een piekgolfindex van 50 tot $85 \%$ ook wel beschouwd als onderdeel van het ESES-spectrum, aangezien kinderen met deze EEG-verschijnselen zich ook vaak presenteren met een ontwikkelingsachterstand. De aard en lokalisatie van epileptiforme afwijkingen varieert van zeer focale piekjes of scherpe golven (figuur I) tot gegeneraliseerde piekgolfcomplexen (figuur 2). De epileptiforme afwijkingen zijn het meest uitgesproken in de non-REM-slaap. Er zijn aanwijzingen dat het al dan niet ontbreken van fysio- logische slaapverschijnselen (slaapspoelen, K-complexen, vertexgolven) bij kinderen met ESES betekenis heeft voor de prognose. Het is ongunstig wanneer deze verschijnselen en het onderscheid tussen de verschillende slaapstadia volledig verdwenen zijn (Boer, 2009). Wanneer er sprake blijkt van ESES en er nog geen oorzaak bekend is, wordt een MRI-hersenen aangeraden en tevens genetische diagnostiek (een Single Nucleotide Poly-morphism array en een focale epilepsie genen-pakket of tenminste analyse ten aanzien van de GRIN2a mutatie). 
Epileptiforme afwijkingen en cognitie

Hoe ESES leidt tot cognitieve stoornissen is niet precies bekend. Een mogelijke hypothese is de zogenaamde 'synaptische homeostase hypothese': in waak neemt de kracht van de synaptische verbindingen in de hersenen toe en worden er nieuwe verbindingen gemaakt (de synapsdichtheid neemt toe door nieuwe ervaringen). In slaap neemt de kracht van deze verbindingen weer af en verdwijnen de minst relevante verbindingen. Deze reorganisatie zorgt ervoor dat het hersennetwerk efficiënt blijft en is daarmee van groot belang voor leergedrag. In het EEG is het aantal en de kracht van de synaptische verbindingen direct gerelateerd aan de slow waves. Slow waves zijn langzame golven in slaap die ontstaan doordat de membraanpotentiaal van veel hersencellen tegelijkertijd oscilleert. Een grotere synapsdichtheid is uit het EEG af te leiden als een grotere helling en amplitudo van de slow waves. De helling en amplitudo van slow waves nemen normaal af gedurende de nacht, wat een afname in aantal synapsen reflecteert en daarmee reorganisatie van het hersennetwerk, zoals schematisch weergegeven in figuur 3 (Tononi \& Cirelli, 2006).
Uit recent onderzoek is gebleken dat deze veranderingen van slow wave-kenmerken gedurende de nacht niet optreden bij kinderen met ESES. Bij kinderen met ESES wordt juist een toename gezien. De hypothese is dat de cognitieve problemen van kinderen met ESES gecorreleerd zijn aan de verstoring van slow wave-kenmerken (Bölsterli et al., 20II). Deze hypothese wordt ondersteund door een recente studie waarin verstoring van slow wave-fysiologie gecorreleerd bleek aan verminderd leervermogen overdag (Boly et al., 2017).

\section{Behandeling}

Het doel van de behandeling van kinderen met ESES is primair het verbeteren van het cognitief functioneren. Aanvallen zijn doorgaans goed te behandelen met anti-epileptica zoals valproïnezuur of levetiracetam. De cognitieve problemen en de grote hoeveelheid epileptiforme afwijkingen in slaap bij kinderen met het ESES-syndroom reageren in de meeste gevallen echter onvoldoende op behandeling met deze anti-epileptica. Op basis van een meta-analyse van (veelal retrospectieve) cohortstudies wordt met deze medicijnen slechts in $34 \%$ van de gevallen verbetering (van

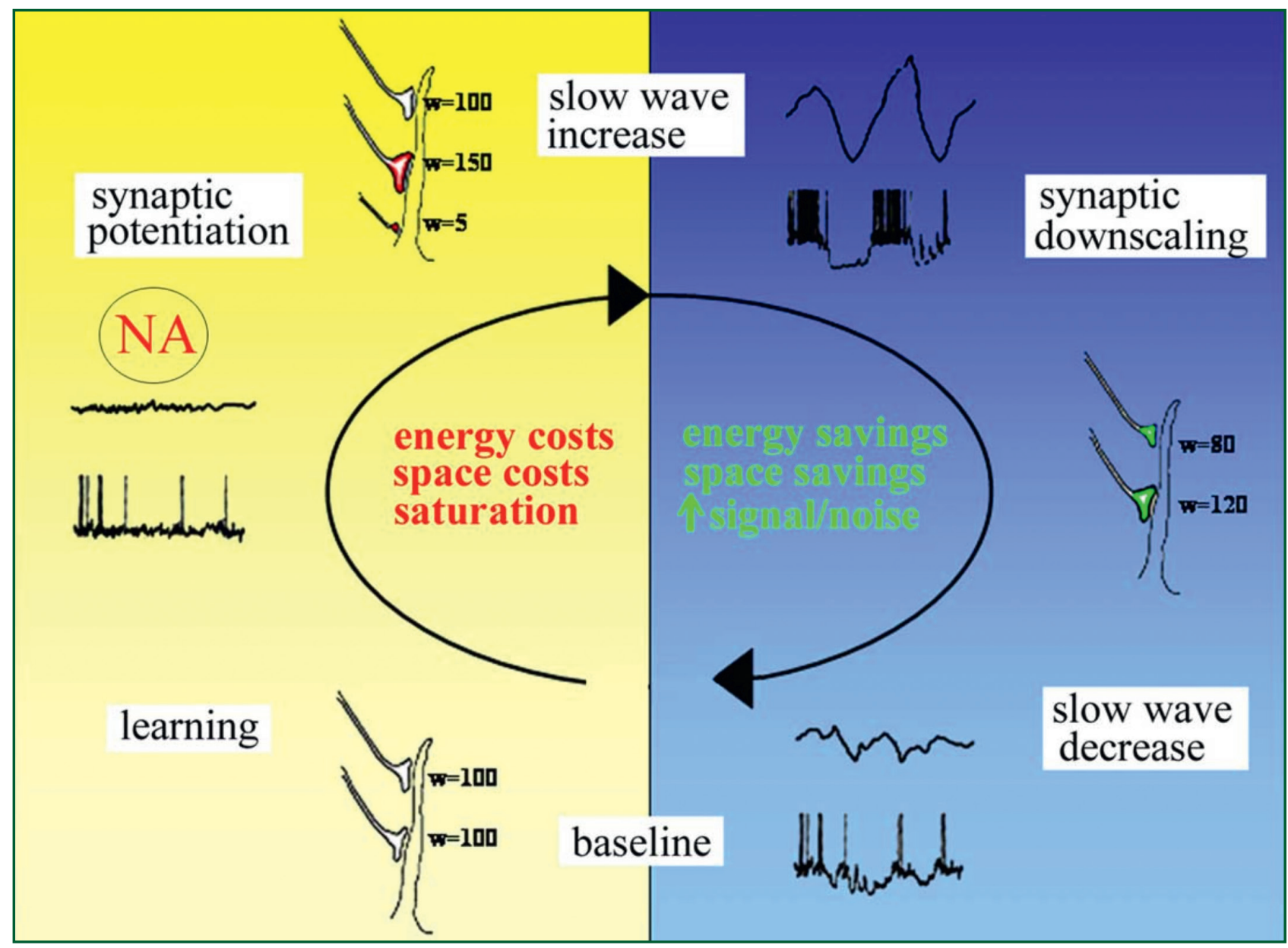

Figuur 3 De synaptische homeostase hypothese: in waak (links) nemen de synaptische verbindingen toe. In het begin van de nachtslaap (rechts) zorgen deze vele verbindingen voor een toename van de amplitude van de slow waves. In de slaap verdwijnen minder belangrijke verbindingen, waardoor het netwerk efficiënt blijft en slow waves aan het eind van de nacht een kleinere amplitude hebben. (Overgenomen uit Tononi et al, 2006). 
EEG of functioneren) bereikt. Benzodiazepines zoals clobazam, waren in $59 \%$ van de gevallen succesvol en zijn momenteel vaak de eerste keuze voor behandeling van ESES. Corticosteroïden gaven in $75 \%$ van de gevallen verbetering van EEG en/of functioneren, maar worden in de praktijk vaak pas gegeven als benzodiazepines niet effectief zijn. Een verklaring voor het effect van corticosteroïden is mogelijk dat inflammatie een rol speelt bij kinderen met ESES (Van den Munckhof et al., 20I6). Bij kinderen met een duidelijke focale en structurele oorzaak van ESES kan chirurgie worden overwogen (verbetering in 93\% van de gevallen) (Van den Munckhof et al., 2015). Aangezien de kwaliteit van de geïncludeerde studies beperkt is en de conclusie dus met voorzichtigheid geïnterpreteerd moet worden, loopt er momenteel een gerandomiseerde studie (RESCUE ESES) ${ }^{\mathrm{I}}$ waarin behandeling met clobazam wordt vergeleken met behandeling met corticosteroïden (geregistreerd onder ISRCTN42686094) met het doel meer bewijs te verkrijgen voor de beste behandeling in een vroege fase van de aandoening.

\section{Prognose}

ESES verdwijnt spontaan in de puberteit. Wel kan er nadien nog sprake zijn van (meestal laag-frequent voorkomende) aanvallen en kan het syndroom overgaan in een andere vorm van epilepsie. Kinderen bij wie geen oorzaak werd gevonden kunnen ook in permanente remissie gaan. De ontwikkelingsachterstand die kinderen met ESES oplopen halen zij echter vaak niet meer in. Er zijn in de literatuur onvoldoende gegevens beschikbaar over de kans op cognitief functioneren binnen de normale grenzen na het verdwijnen van ESES. De beschreven uitkomsten variëren van volledig normaal tot een ernstige verstandelijke beperking en worden mede beïnvloed door de inclusiecriteria (onder andere wel/geen structurele afwijkingen, afkapwaarde SWI). Wel blijkt de prognose relatief gunstig wanneer de duur van de aandoening beperkt is. Daarom zijn tijdige opsporing en adequate behandeling van groot belang (Maltoni \& Parmeggiani, 20I6).

\section{Tot slot}

Door slaap geïnduceerde interictale epileptiforme activiteit komt voor bij $2 \%$ van de gezonde kinderen. Een hogere prevalentie (20-65\%) wordt beschreven bij kinderen met een diversiteit aan ontwikkelingsstoornissen, waaronder ADHD, autisme en taalontwikkelingsstoornis (Silvestri et al., 2007). Een evidente relatie tussen de epileptiforme activiteit en de symptomen werd bij deze kinderen nooit aangetoond. Er wordt daarom aanbevolen om slaap-EEG niet op te nemen in de routine-diagnostiek van deze groepen patiënten. Wel is bij een stagnatie of regressie van cognitief functioneren alertheid geboden. De diagnose epileptische encefalopathie met ESES dient echter alleen te worden gesteld wanneer sprake is van een forse toename van epileptiforme afwijkingen in slaap, in combinatie met een achteruitgang van taal, cognitie of het ontstaan van gedragsproblemen.

\section{Referenties}

Agarwal Ret al. (2016) Thalamic abnormalities in children with continuous spike-wave during slow-wave sleep: An F-I8-fluorodeoxyglucose positron emission tomography perspective, Epilepsia, 57(2), pp. 263-271. doi: 10.1111| epi.13278.

Boer MS (2009) Guidelines for EEG in encephalopathy related to ESES / CSWS in children, 50, pp. 13-17. doi: $10.1111 / j .1528-1167.2009 .02211 . x$.

Bölsterli BK et al. (20II) 'Impaired slow wave sleep downscaling in encephalopathy with status epilepticus during sleep (ESES), Clinical Neurophysiology, 122(9), pp. 17791787. doi: 10.1016/j.clinph.2011.01.053.

Boly M et al. (2017) Altered sleep homeostasis correlates with cognitive impairment in patients with focal epilepsy., Brain, I4O(4), pp. I026-I040. doi: Io.I093/brain/ awxoI7.

Commission on Classification and Terminology of the International League Against Epilepsy (I989) Proposal for Revised Classification of Epilepsies and Epileptic Syndromes., Epilepsia, 30(4), pp. 389-399. doi: 10.1111/j. 1528-1157.1989.tb05316.x.

Fernández IS et al. (2013) The tower of Babel: Survey on concepts and terminology in electrical status epilepticus in sleep and continuous spikes and waves during sleep in North America, Epilepsia, 54(4), pp. 741-750. doi: 10.1111/epi.12039.

Kersbergen KJ et al. (2013) Neonatal thalamic hemorrhage is strongly associated with electrical status epilepticus in slow wave sleep, Epilepsia, 54(4), pp. 733-740. doi: 10.1111/epi.12131.

Landau WM, Kleffner FR (1957) Syndrome of acquired aphasia with convulsive disorder in children., Neurology. Not Available, 7(8), p. 1241, 8 pages following 1241. doi: $10.1212 / \mathrm{WNL} \cdot 7.8 .523$.

Lemke JR et al. (2013) 'Mutations in GRIN2A cause idiopathic focal epilepsy with rolandic spikes',. Nature Publishing Group, 45(9), pp. 1067-1072. doi: 10.10381 ng. 2728 .

Maltoni L, Posar A, Parmeggiani A (2016) 'Long-term follow-up of cognitive functions in patients with continuous spike-waves during sleep (CSWS)', Epilepsy \& Behavior. Elsevier Inc., 6o, pp. 211-217. doi: 10.1016/j. yebeh.2016.04.006.

${ }^{1}$ Als u een nieuwe patiënt met ESES ziet, zouden wij overleg over mogelijke inclusie in de RESCUE ESES-studie zeer waarderen. 
Van den Munckhof B. et al. (2015) 'Treatment of electrical status epilepticus in sleep: A pooled analysis of 575 cases', Epilepsia, 56(11), pp. 1738-1746. doi: 10.1111/ epi.13128.

Van den Munckhof B et al. (20r6) Serum inflammatory mediators correlate with disease activity in electrical status epilepticus in sleep (ESES) syndrome, Epilepsia, 57(2), pp. e45-e50. doi: 10.1111/epi.13274.

Nickels K, Wirrell E (2008) Electrical Status Epilepticus in Sleep, Seminars in Pediatric Neurology, 15(2), pp. 50-6o. doi: $10.1016 / j$.spen.2008.03.002.

Patry G, Lyagoubi S, Tassinari CA (I97I) Subclinical “electrical status epilepticus" induced by sleep in children, Archives of Neurology, 24(3), pp. 242-252. doi: http:/|dx.doi. org/10.1001/archneur.1971.00480330070006.

Saltik S et al. (2005) A clinical and EEG study on idiopathic partial epilepsies with evolution into ESES spectrum disorders, Epilepsia, 46(4), pp. 524-533. doi: 10.1111/j. 0013-9580.2005.45004.x.

Sánchez Fernández I et al. (20I2) Electrical status epilepticus in sleep: Clinical presentation and pathophysiology, Pediatric Neurology. Elsevier Inc., 47(6), pp. 390-410. doi: 10.1016/j.pediatrneurol.2012.06.016.

Sánchez Fernández I et al. (20I7) Reduced thalamic volume in patients with Electrical Status Epilepticus in Sleep, Epilepsy Research. Elsevier B.V., 130, pp. 74-80. doi: 10.101 6/j.eplepsyres.2017.01.010.

Silvestri R et al. (2007) Ictal and interictal EEG abnormalities in ADHD children recorded over night by videopolysomnography, Epilepsy Research, 75(2-3), pp. 130-137. doi: 10.1016 jj.eplepsyres.2007.05.007

Tononi G, Cirelli C (2006) Sleep function and synaptic homeostasis, Sleep Medicine Reviews, 10(1), pp. 49-62. doi: 10.1016/j.smrv.2005.05.002.

Door: Rick van Lanen (rick.van.lanen@mumc.nl), Christianne Hoeberigs, Noël Bauer, Roel Haeren, Govert Hoogland, Albert Colon, Céline Piersma, Jim Dings, Olaf Schijns, neurochirurgie, Maastricht Universitair Medisch Centrum, Maastricht.

\section{Gezichtsvelduitval na epilepsie- chirurgie: een nieuwe scorings- methode}

Anterieure temporaalkwabresectie als behandeling voor medicatie-resistente epilepsie kan gezichtsvelduitval veroorzaken. Deze uitval bestaat uit een homonieme contralaterale bovenste kwadrantanopsie, ook wel een 'pie in the sky' genoemd. De incidentie varieert van $15 \%$ tot $90 \%$. In deze bijdrage wordt een kwantitatieve perimetrie-methode beschreven om postoperatieve gezichtsvelduitval te kwantificeren. Deze werd toegepast bij 55 patiënten die een temporaalkwabresectie ondergingen.

\section{Epilepsiechirurgie en gezichtsvelduitval}

Epilepsiechirurgie voor patiënten met temporaalkwabepilepsie is bijzonder effectief, met aanvalsvrijheidspercentages van 70-80\% (Moura et al., 2016). Een chirurgische optie voor temporaalkwabepilepsie is een anterieure temporaalkwabresectie (anterieure temporaal lobectomie, ATL) met of zonder resectie van de amygdala en hippocampus (amygdalohippocampectomie). Mogelijke complicaties van deze behandeling zijn onder andere gezichtsvelduitval (GVU), cognitieve klachten, neurologische uitval, en infecties (Bjellvi et al., 20I5). De meest beschreven GVU is een contralaterale homonieme bovenste kwadrantanopsie, klinisch ook wel een 'pie in the sky' genoemd (Duncan, 2007).

De incidentie van deze postoperatieve GVU wisselt sterk, met gerapporteerde percentages in de literatuur van I5 tot 90\% (Jeelani et al., 2010). De uitval wordt veroorzaakt door schade aan het anterieure deel van de radiatio optica, die van het corpus geniculatum laterale van de thalamus ombuigt naar het voorste deel van de temporaalkwab, onderweg naar de visuele cortex. Deze anterieure bocht van de radiatio optica wordt 'Meyer's loop' (ML) genoemd (Meyer, I907). De afstand tussen het voorste deel van ML en de temporaalpool varieert van 22 tot $44 \mathrm{~mm}$. Aangezien de lengte van een temporaalkwabresectie maximaal 9omm naar dorsaal kan zijn, gemeten vanaf de temporaalpool, kan de 'Meyer's loop' hiermee gemakkelijk beschadigd worden (Krolak-Salmon et al., 2000). Desalniettemin staat het nog steeds ter discussie of de lengte van resectie correleert met de mate van gezichtsvelduitval (Hensley-Judge et al., 2013). Ook is er geen consensus over het bepalen van de mate van GVU na ATL. De bestaande methoden categoriseren de uitval kwalitatief in brede groepen, zonder dat 